\title{
Implementation of multidrug therapy in the ALERT Leprosy Programme in the Shoa Region of Ethiopia. First results with paucibacillary patients
}

\author{
MARIJKE BECX-BLEUMINK \\ All Africa Leprosy and Rehabilitation Training Centre (ALERT), \\ Addis Ababa, Ethiopia
}

Accepted for publication 18 September 1985

\begin{abstract}
Summary Multidrug therapy (MDT) was introduced in the ALERT Leprosy Control Programme in January 1983, using the regimens recommended by the World Health Organization (WHO). During the period 1 January-30 June 1983 1684 paucibacillary patients started their course of MDT in two districts in the north-eastern part of the Shoa Region. 1501 patients (89.1\%) completed their 6month course of treatment within a period of 9 months. Although there are some communication problems in the area the implementation of MDT with a once monthly supervised component has proved to be feasible; in only 1 of the 65 clinics which were involved did less than $70 \%$ of the patients complete their course of MDT.

This paper discusses the results of implementation of MDT for paucibacillary patients.
\end{abstract}

\section{Introduction}

The ALERT Leprosy Control programme is responsible for the leprosy control activities in the Shoa Administrative Region. This region is located centrally in Ethiopia with Addis Ababa as its capital; it covers $85,500 \mathrm{sq} \mathrm{km}$ with a population of 8.75 million.

There are 296 leprosy treatment centres in the region; 170 are attached to the general medical services and 126 are leprosy clinics which have been established in those areas where as yet no general medical service exists. Fifty percent of the leprosy centres are accessible by car throughout the year; $32 \%$ are accessible by car only during the dry season and $18 \%$ can be reached only on foot or on muleback. Almost all clinics are conducted by special leprosy staff. The majority of them are health assistants who, besides a general medical training, have received special training in leprosy. At the beginning of 1983 the number of leprosy patients registered in the region was 19,498. 
Multidrug Therapy (MDT) is being introduced gradually into the region. In January 1983 the introduction of MDT started in the north-eastern part of the region and involved both paucibacillary and multibacillary patients. In this paper the first results of implementation of MDT for paucibacillary patients are discussed. Paucibacillary patients are defined as those patients who are clinically TT, BT and I, according to the Ridley-Jopling Classification, and who have a Bacteriological Index (BI) of less than 2 at any site and at any time.

The MDT regimen recommended by the World Health Organization (WHO) ${ }^{1}$ for paucibacillary patients is given to patients: $600 \mathrm{mg}$ rif ampicin, every 4 weeks under supervision, and $100 \mathrm{mg}$ dapsone daily, self-administered; for 6 months. In September 1983 it was decided that the 6 months of treatment should be completed in a period not exceeding 9 months.

\section{The MDT programme in the Debre Berhan area}

\section{The Area}

The Debre Berhan area consists of Tegulet \& Bulga, Yifat \& Timuga and Menz \& Gishe districts. In January 1983 the MDT programme was launched in the 37 clinics of Tegulet \& Bulga, the 27 clinics of Yif at \& Timuga and in 1 clinic of Menz $\&$ Gishe districts. The population of the area covered is about 920,000; geographically most of the people live in the depths of the valleys.

The 65 clinics are 2 hospital clinics, 3 health centres, 27 health stations and 33 leprosy clinics. Thirty clinics are accessible by car throughout the year; 18 clinics (7 health stations and 11 leprosy clinics) are accessible by car only during the dry season and 17 clinics ( 3 health stations and 14 leprosy clinics) can be reached only on foot or on muleback. Twenty-eight clinics are conducted at weekly intervals, 31 clinics at fortnightly intervals and 6 clinics once every 4 weeks.

\section{The resources}

The following resources were available in the area.

Manpower: 1 field coordinator, in charge of the programme; 1 senior supervisor; 2 acting supervisors; 9 health assistants, 3 staff of the Extended Programme of Immunization (EPI); 1 clerk; and 2 drivers.

In November 1983 the field coordinator was withdrawn from the area after he had initiated and supervised the initial phases of implementation of the programme. In March 19841 acting supervisor and 1 driver were transferred to Addis Ababa.

Transport: At the start of the programme 3 cars were available; after a few months 2 additional cars were made available. One of the additional cars was withdrawn with the field coordinator and one with the acting supervisor. 


\section{The patients}

Two-hundred-and-two patients were excluded from MDT, mainly due to old age, severe disabilities or working conditions, or because they were unable to attend every 4 weeks for the supervised treatment. Two patients were excluded because of irregular attendance for anti-tuberculosis treatment.

Twenty-six patients were released from dapsone monotherapy prior to the introduction of MDT. Release criteria were based on the recommendations made by the WHO Expert Committee in its fourth report (No. 459, 1970). ${ }^{2}$ However, as many patients had not been reviewed regularly, it appeared impossible to apply these criteria. It was then decided to put all paucibacillary patients, who were able to attend the clinics every 4 weeks, on MDT.

During the first 6 months of 19831766 paucibacillary patients started their 6months' course of MDT. Due to positive skin smear results, 82 patients who were initially classified as paucibacillary, were reclassified as multibacillary patients, 24 months after the start of MDT. Their treatment was changed accordingly. For the remaining 1684 patients the period of dapsone monotherapy prior to MDT is given in Table 1.

Patients who were noncompliant were pursued by contact with the Farmers' Associations and personal visits by other patients. Patients who had completed their course of MDT before September 1983 were given a release from treatment certificate and were told to come back at any time if they experienced problems or developed a new activity of the disease. From October 1983 patients were given appointment dates for follow-up examinations after release from MDT. Patients who were released prior to this date were instructed through other patients to come for regular follow-up examinations.

Reorganization of the leprosy control activities in the area

Before MDT was introduced all patients were clinically examined and for those

Table 1. Period of dapsone prior to MDT

\begin{tabular}{cc} 
Period of dapsone & No. of patients \\
\hline None & $95 / 74 \mathrm{BT}, 21 \mathrm{TT}$ \\
$-2 \mathrm{yr}$ & 212 \\
$2-5 \mathrm{yr}$ & 341 \\
$>5 \mathrm{yr}$ & 804 \\
Unknown & 232 \\
\hline
\end{tabular}


who did not have a clinical record card one was filled in with the clinical signs noted at the time of assessment.

The clinical classifications which were available were checked with previous recorded and present signs. Patients classified as B were reclassified BT or BL. In order to be on the safe side a small number of B patients who could not be reclassified were classified $\mathrm{BL}$.

Skin smears from paucibacillary patients were only taken 2-4 months after the start of MDT. Because of positive skin smear results 82 patients were reclassified as multibacillary patients. A central register was prepared in which all patients who were put under MDT were entered. Treatment register, patients record cards and other recording systems which were already in use in the dapsone monotherapy programme were adapted for the MDT programme.

At the start of MDT detailed instructions for implementation had not been formulated. In October 1983 a 'Manual for implementation of Multiple Drug Therapy (MDT) in Ethiopia' ${ }^{3}$ was prepared by senior staff of the National Leprosy Control Programme and the ALERT Leprosy Control Programme; in cooperation with a short-term WHO consultant. After the manual was finalized the recording and reporting systems described in the manual were introduced. The staff received additional training concerning the new regimens, organizational, recording and reporting aspects. It was decided that only a limited number of the staff, the supervisors and a few experienced health assistants, should be made responsible for giving out the supervised treatment. A small stock of drugs was given to all staff in order to ensure that patients would receive their treatment if a supervisor or one of the other assigned staff could not attend the clinic. In all clinics the supervised treatment is given out once every 4 weeks. Patients who fail to attend during those days can still receive the rifampicin up to 2 weeks after the scheduled clinic days and the dapsone at any time. In weekly and fortnightly clinics the other 3 or 1 clinic day(s) are for late comers, for patients who have problems, for those who need care for disabilities and for health education activities in the communities.

Clinical assessment of patients at the end of the treatment period was done only by supervisors, who also decided about release from treatment or discontinuation of the treatment in cases of irregularity of attendance.

Patients who developed complications which required hospital admission were seen by a supervisor, either at the clinic or at the area headquarters, before they were referred to the ALERT Hospital.

Prior to the start of MDT extensive health education was given to the patients concerning the new treatment. Furthermore, health education campaigns were organized in villages, during meetings with the Farmers' Associations and during political meetings. 


\section{Results}

An analysis of the completion of the treatment of the 1684 patients who started their course of MDT during the period 1 January-30 June 1983 is given in Table 2. The 1501 patients who completed their course of MDT within a period of 9 months include 86 of the 95 patients who did not receive dapsone monotherapy prior to MDT. Information about the percentages of patients who, after different periods of dapsone monotherapy, completed their course of MDT was not collected.

An analysis of the percentages of the patients who completed their course of MDT in the 65 clinics is given in Table 3. As we were interested to know whether accessibility of the clinic, type of clinic, frequency of leprosy clinic days and the number of patients on treatment, related to the percentages of patients who completed their course of MDT, further analyses were made (Tables 4, 5, 6 and 7). With the use of the variance analysis test no statistically significant relation could be found between these factors and the percentage of successful completion of treatment.

In the field $4 \mathrm{BT}$ patients were diagnosed with a reversal reaction involving the nerves. None of them had received dapsone monotherapy prior to MDT. Two patients developed the reversal reaction while on MDT, and 2 patients after release from MDT. In none of the patients who had received dapsone monotherapy prior to MDT was a reversal reaction diagnosed. Severe side-effects of the drugs were not reported in the group of 1684 paucibacillary patients.

We expect that because more than $90 \%$ of these patients reported themselves with leprosy in the past, they will also do so in the case of renewed activity of the disease. So far about $9 \%$ of the patients who were expected for follow-up examination have come once or twice after their release from MDT. One BT patient who did not receive dapsone prior to MDT and who developed a reversal reaction $2 \frac{1}{2}$ months after release from treatment, was diagnosed as a relapse patient in the hospital. Our experienced clinical staff however, are of the opinion that this patient did not have a relapse. The severe drought situation, which has affected main parts of the Debre Berhan area, definitely contributes to the low attendance after release from treatment. Accessibility of the clinic, types of clinic, frequency of leprosy clinic days and the number of patients on treatment did not show a statistically significant relation with the percentages of patients who completed their course of MDT. At the same time that the backlog of multibacillary patients are released from MDT, the number of patients under leprosy treatment will be reduced by about $80 \%$. However, regular follow-up examinations of patients after their release from treatment and the care for patients with disabilities of whom all but a few will not be under leprosy treatment any more, will continue to keep the workload high during the coming years.

The picture of long lines of patients waiting for their treatment belongs to the past, some years after the introduction of MDT. It seems logical that more 
Table 2. Analysis of the completion of MDT

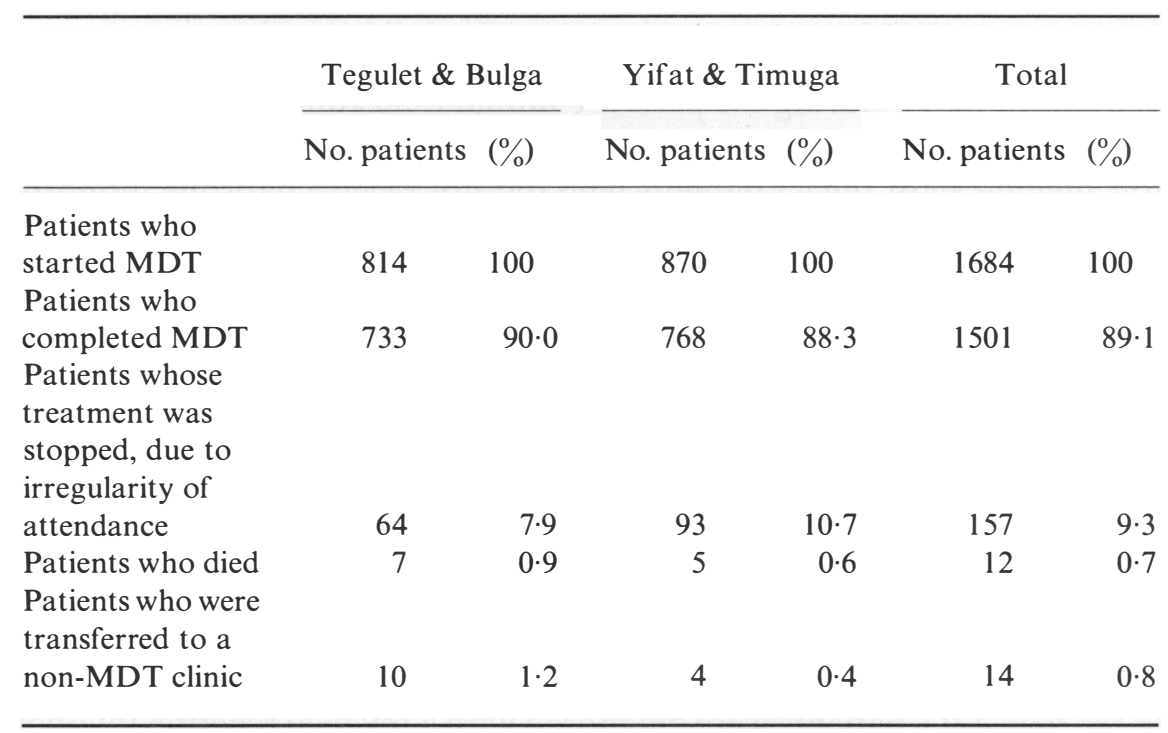

Table 3. Percentage completion of MDT in the 65 clinics

\begin{tabular}{cc} 
Completion of treatment $(\%)$ & No. of clinics \\
\hline 100 & 18 \\
$91-99$ & 14 \\
$81-90$ & 22 \\
$71-80$ & 10 \\
$61-70$ & 1 \\
\hline
\end{tabular}

Table 4. Percentage completion of treatment and accessibility

\begin{tabular}{cccc}
$\begin{array}{c}\text { Completion } \\
\text { of } \\
\text { treatment }\end{array}$ & $\begin{array}{c}\text { No. of clinics } \\
\text { accessible } \\
\text { whole year }\end{array}$ & $\begin{array}{c}\text { No. of clinics } \\
\text { accessible in dry } \\
\text { season }\end{array}$ & $\begin{array}{c}\text { No. of clinics } \\
\text { not accessible }\end{array}$ \\
\hline 100 & 9 & 2 & 7 \\
$91-99$ & 5 & 6 & 3 \\
$81-90$ & 10 & 7 & 5 \\
$71-80$ & 6 & 2 & 2 \\
$61-70$ & - & 1 & - \\
\hline
\end{tabular}


Table 5. Percentage completion of treatment and type of clinic

\begin{tabular}{cccc}
$\begin{array}{c}\text { Completion } \\
\text { of treatment }\end{array}$ & $\begin{array}{c}\text { Hospitals } \\
\text { Health Centres }\end{array}$ & Health Stations & Leprosy Clinics \\
\hline 100 & 2 & 7 & 9 \\
$91-99$ & 2 & 5 & 7 \\
$81-90$ & 1 & 11 & 10 \\
$71-80$ & - & 4 & 6 \\
$61-70$ & - & - & 1 \\
\hline
\end{tabular}

Table 6. Percentage completion of treatment and frequency of leprosy clinic days

\begin{tabular}{crrc}
\hline $\begin{array}{c}\text { Completion } \\
\text { of treatment }(\%)\end{array}$ & Weekly & Fortnightly & Monthly \\
\hline 100 & 5 & 10 & 3 \\
$91-99$ & 8 & 6 & - \\
$81-90$ & 12 & 9 & 1 \\
$71-80$ & 3 & 6 & 1 \\
$61-70$ & - & - & 1 \\
\hline
\end{tabular}

Table 7. Percentage completion of treatment and number of patients on MDT

\begin{tabular}{cccccc}
$\begin{array}{c}\text { Completion } \\
\text { of } \\
\text { treatment }\end{array}$ & $\begin{array}{c}\text { No. clinics } \\
0-9 \\
\text { patients }\end{array}$ & $\begin{array}{c}\text { No. clinics } \\
10-19 \\
\text { patients }\end{array}$ & $\begin{array}{c}\text { No. clinics } \\
20-29 \\
\text { patients }\end{array}$ & $\begin{array}{c}\text { No. clinics } \\
30-39 \\
\text { patients }\end{array}$ & $\begin{array}{c}\text { No. clinics } \\
\geqslant 40 \\
\text { patients }\end{array}$ \\
\hline 100 & 9 & 7 & 1 & 1 & - \\
$91-99$ & - & 2 & 3 & 5 & 4 \\
$81-90$ & 1 & 2 & 5 & 8 & 6 \\
$71-80$ & 4 & 2 & 2 & - & 2 \\
$61-70$ & - & 1 & - & - & - \\
\hline
\end{tabular}

attention is paid to an active approach towards prevention of severe disabilities in patients who have a slight or moderate disability at the time of release from treatment; while continuing to give high priority to controlling the disease in the communities. Furthermore, for reasons of cost, consideration should be given to decreasing the frequency of leprosy clinic days. The results that the frequency 
with which leprosy clinics are conducted did not show a statistically significant relation with the percentage of patients who completed their course of MDT deserve careful consideration.

In the group of $74 \mathrm{BT}$ patients who did not receive dapsone monotherapy prior to MDT 4 patients were diagnosed with a reversal reaction which involved the nerves. In the group of patients who received dapsone prior to MDT no reversal reactions were reported. It should be kept in mind that in some patients a reversal reaction could have been missed, especially in those patients who did not complete their course of MDT. It is too early yet to draw conclusions about the occurrence of reversal reactions during and after MDT. More patients should be followed up in a carefully designed and regularly supervised study.

We plan to start soon a study on the occurrence of reactions in patients who receive MDT only. It has been our experience that the preparation of detailed guidelines about the different aspects of MDT, before MDT is implemented, is of extreme importance in order to guarantee smooth running of the programme. In our situation such guidelines were prepared 9 months after the introduction of MDT. However at that time most of the operational weaknesses could be corrected.

Incomplete recording of clinical signs and classification in the past, together with the fact that during the dapsone era skin smears were not routinely examined from all patients at the start of their treatment, made it impossible to get the right classification of all patients at the time of assessment for MDT.

It cannot be overstressed that with the introduction of MDT correct classification of patients is essential. For this, skilled and experienced staff are a must, as are sufficient laboratory facilities for examination of skin smears, including a built-in system of quality control.

\section{Discussion}

The results show that implementation of MDT for paucibacillary patients has been successful in the Debre Berhan area; $89.1 \%$ of the patients who started MDT during the period 1 January-30 June 1983 completed their 6 months' course within a period of 9 months. No difference was found between the percentages of patients who did not receive dapsone monotherapy prior to MDT as compared to patients who received dapsone. Despite communication problems in the area, implementation of MDT with a monthly supervised component has proved to be feasible; in only 1 out of the 65 clinics did less than $70 \%$ of the patients complete their course of MDT.

\section{Acknowledgments}

I wish to thank Ato Getahun Jaffero, the field coordinator, Ato Albejo Olbemo, 
Ato Endale Alemayhu, Ato Endale Emeshaw and Ato Getachew Biru, the supervisors and the health assistants of the Debre Berhan area for their hard work and dedication with which they have carried out the MDT programme often under difficult field circumstances. My thanks also go to the staff of the ALERT Laboratory for reading the many skin smears, to $\mathrm{Mr} \mathrm{H}$ van Dijk, Mr G J Boeke and Miss C Fiedeldey for doing the evaluation about reactions, to $\mathrm{Mr}$ W 't Mannetje for the statistical analysis and to Woizero Alemi for the typing.

\section{References}

1 WHO Technical Report Series No. 675, 1982.

2 WHO Technical Report Series No. 459, 1970.

${ }^{3}$ Manual for Multiple Drug Therapy (MDT) in Ethiopia, National Leprosy Control Programme, 1983. 